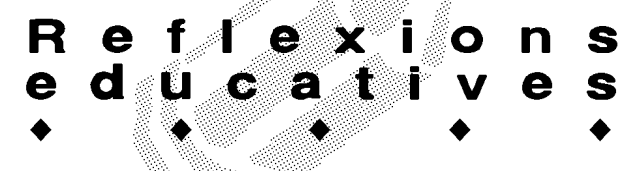

\title{
ESQUEMES PER SABER QUÈ FER I QUÈ DIR EN LLENGUA ESTRANGERA: UN EXEMPLE EN FRANCÈS
}

\author{
Jacky Verrier Delahaie. Àrea de Didàctica de la Llengua i la Literatura. URV
}

\section{Parlem com volem?}

Per als intercanvis comunicatius de cada dia, es necessita conèixer les rutines i les normes de comportaments comunicatius i lingüístics sense els quals podem caure en el fracàs comunicatiu, com en el cas d'aquell estranger que diu al cap de personal d'una empresa: "Jefe, dame trabajo". Saber comunicar a diari és com un joc que s'aprèn des de petit a casa, a l'escola, entre amics... Aquest joc només té èxit si els jugadors coneixen les regles del joc i les respecten. Qui no ha tingut a l'estranger aquesta sensació estranya de dubte i desconfiança en si mateix davant d'una situació familiar en la cultura materna, però que esdevé desconeguda en la cultura estrangera, com per exemple anar a un restaurant, comprar un billet de tren o simplement parlar per telèfon? La llengua no és aquí l'únic obstacle, sinó que podríem dir que el coneixement de la llengua no implica saber utilizar aquesta llengua, o dit d'una altra manera, saber comportarse en la llengua estrangera.

Així, l'èxit de l'intercanvi (èxit, per que tot professor desitja que els seus alumnes assoleixin una bona competència en llengua estranjera tan en l'aspecte purament lingüístic com comunicatiu) requereix reconèixer l'altre com un possible interlocutor vàlid, i si aquesta primera fase es compleix, donarà lloc a la construcció i manteniment de les relacions, amb l'objectiu final d'establir una integració mútua en el teixit cultural d'una o altra llengua.

Les accions diàries que fem sols o en grup no són improvisades, i no es fan de forma desordenada: segueixen un ordre, com les escenes d'una obra de teatre. Aquestes accions, que s'anomenen scripts i que podem definir com les representacions mentals que organitzen el desenvolupament jeràrquic d'una seqüència d'accions, permeten als interlocutors predir aquestes accions i per tant definir després la llengua que les acompanyarà. Alguns autors parlen de guió (LE NY, 1989), altres de script (ABELSON, 1981; CORSON, 1990) o d'esquemes (GAONAC'H, 1987), o de camps d'experiències (GALISSON, 1991).

\section{Els esquemes en l'aprenentatge d'una llengua estrangera}

Sense aprofundir més en el tema i per abordar aspectes pràctics, heus aquí un exemple d'esquema (el restaurant) que permet observar com es desenvolupen les accions que generalment es realitzen en un lloc com aquest (Fig. 1).

Hem triat el restaurant perquè és una situació on la llengua utilitzada és neutra i molt rutinària, és a dir, no comporta una implicació cultural molt forta per part dels participants, a més de ser sovint semblant en països europeus.

\section{ALLER AU RESTAURANT}

\begin{tabular}{|l|l|l|}
\hline \multirow{2}{*}{ ACTIONS } & Production & langagière \\
\hline & Le serveur & Le client \\
\hline ouvrir la porte & & \\
\hline entrer & & \\
\hline attendre le serveur & & \\
\hline demander une table & & \\
\hline choisir une table & & \\
\hline enlever son manteau & & \\
\hline se diriger vers la table & & \\
\hline s'installer & & \\
\hline saluer & & \\
\hline regarder autour de soi & & \\
\hline demander la carte & & \\
\hline consulter la carte & & \\
\hline choisir le menu & & \\
\hline appeler le serveur & & \\
\hline attendre & & \\
\hline commander le menu & & \\
\hline boire l'apéritif & & \\
\hline manger & & \\
\hline boire & & \\
\hline demander l'addition & & \\
\hline payer & & \\
\hline prendre son manteau & & \\
\hline dire au revoir & & \\
\hline
\end{tabular}

Fig. 1. Model d'esquema en l'aprenentatge d'una llengua estrangera 


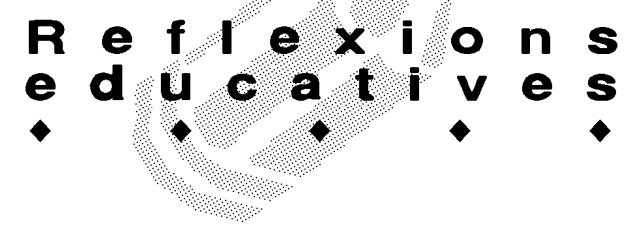

De moment només tenim la descripició de les accions verbals i no-verbals de l'escript per tal de saber què fer i què dir generalment en un restaurant, en aquest cas a França.

Aplicat a la classe podem dir que:

1. Aquesta primera fase a) dóna a conèixer als alumnes les consignes a seguir en aquesta situació, b) permet descobrir les diferències i semblances entre els comportaments d'aquí $i$ d'allà i c) crea un ambient de seguretat, ja que el saberfer pot ajudar al saber-dir. Aquest últim punt ens permet dir que l'alumne que sap allò que ha de fer tindrà menys dificultats per dir allò que ha de dir.

2. El saber comportamental és en moltes situacions una condició prèvia al saber què dir i com s'ha de dir. Direm, per tant, que el domini de les seqüències d'accions permet accedir mès fàcilment $a$ l'ús de la llengua.

3. Aquesta perspectiva d'ensenyament i aprenentatge no és sempre present a la classe on avui predomina l'expressió (lliure?) de l'alumne. Avui, l'alumne ha de parlar, les directrius oficials donen preferència a la llengua oral, cosa certament interessant, però no parlem mai com volen; sempre tenim al darrere nostre les normes de comportaments lingüístics i els altres que ens avaluen constantment, com nosaltres avaluem la parla dels altres.

4. És cert que les tècniques de simulacions van encetar el camí del guions en l'aprenentatge d'una llengua estrangera, però no van donar lloc a estudis sistemàtics.

5. El fet de no saber com comportar-se lingüísticament en la llengua estrangera que s'aprèn pot conduir a una situació de classe ben coneguda, que diu que l'alumne parla en una llengua (la llengua estrangera), però es comporta en una altra (la llengua materna).

6. Quin professor no ha tingut mai aquesta insatisfacció al comprovar intuïtivament després d'una simulació (anar a comprar pa a la fleca, per exemple) que falta alguna cosa en el diàleg, que les frases no són aquelles que diria un anglès, un francès 0 un alemany, i que les accions no són aquelles que coneixem d'aquesta situació.

7. Però és clar que quan un professor utilitza la simulació a classe, no pensa sempre què s'ha de fer en aquest cas, i per tant és normal que els alumnes es comportin com si fos una situació de la seva cultura, i que la llengua sigui influenciada per aquest fet.

8. No pretenem tampoc que els alumnes es transformin en petits anglesos, francesos o alemanys, sinó que, per ser coherent amb la famosa comunicació que es vol ensenyar a l'escola, hi hem d'introduir tots els aspectes que configuren l'intercanvi comunicatiu, i no solament la part lingüística.

9. Finalment, un ensenyament basat en els valors $i$ en la interculturalitat, la comprensió i el respecte de l'altre ha d'introduir en els seus principis el coneixement de "com funciona l'altre" tant en la llengua o com en les seves accions.

Si després de tenir en compte aquests principis introduïm el llenguatge en l'esquema anterior, podríem tenir un diàleg com el que es mostra a la figura 2.

\section{L'espai conversacional compartit}

Un ensenyament que té en compte els principis esmenats anteriorment ha d'afegir també que la comunicació no és solament una qüestió de llengua o de normes socioculturals. Al darrere d'una llengua hi ha persones, amb la seva mentalitat $i$ el seu estat d'ànim, i gent que es coneix bé, uns altres poc i uns altres gens. També hi té a veure el lloc (sorolls,

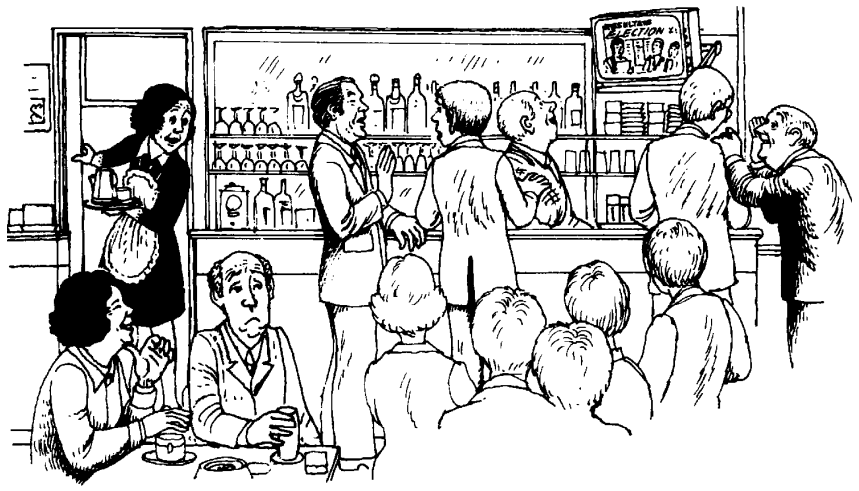

silencis...) i el temps (un pot tenir pressa o no). Aquestes circumstàncies influeixen en la formar de parlar, el vocabulari que s'utilitza, l'entonació, el ritme de la veu, la quantitat de llenguatge utilitzat... Imaginem que un francès ens demana on hi ha un bon restaurant. Si tenim pressa, li podem constestar: "là, à droite de la place, il y a le restaurant...”. Si tenim temps, li podem indicar diferents llocs: al centre de la ciutat, als afores, a prop de la platja, a cinc quilòmetres, a la carretera de...

L'Espai Conversacional Compartit pretén tenir en compte aquestes circumstàncies. Parlem d'Espai Con- 


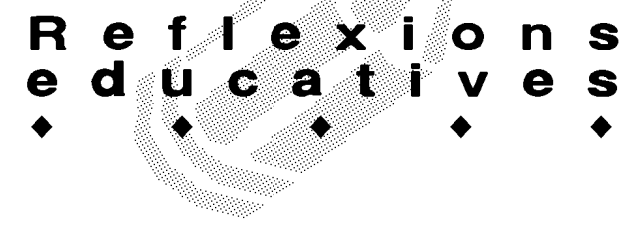

\begin{tabular}{|c|c|c|}
\hline $\begin{array}{l}\text { ACTIONS VERBALES } \\
\text { ET NON-VERBALES }\end{array}$ & $\begin{array}{l}\text { Production } \\
\text { Le serveur }\end{array}$ & $\begin{array}{l}\text { langagière } \\
\text { Le client }\end{array}$ \\
\hline \multicolumn{3}{|l|}{ ouvrir la porte } \\
\hline \multicolumn{3}{|l|}{ entrer } \\
\hline \multicolumn{3}{|l|}{ saluer } \\
\hline attendre le serveur & Bonjour. & Bonjour. \\
\hline demander une table & $\begin{array}{l}\text { Vous êtes } \\
\text { combien? }\end{array}$ & On est deux. \\
\hline choisir une table & $\begin{array}{l}\text { Il y une table } \\
\text { libre ici. }\end{array}$ & Merci. \\
\hline \multicolumn{3}{|l|}{ enlever son manteau } \\
\hline \multicolumn{3}{|l|}{ se diriger vers la table } \\
\hline \multicolumn{3}{|l|}{ s'installer } \\
\hline saluer & $"$ & $\begin{array}{l}\text { geste de la } \\
\text { tête ou dire } \\
\text { "messieurs } \\
\text { dames" ou } \\
\text { "bonjour". }\end{array}$ \\
\hline \multicolumn{3}{|l|}{ regarder autour de soi } \\
\hline demander la carte & $\begin{array}{l}\text { 2. Oui, bien } \\
\text { sûr, voilà. }\end{array}$ & $\begin{array}{l}\text { 1. Monsieur, } \\
\text { (Mademoise- } \\
\text { lle), vous avez } \\
\text { una carte, s'il } \\
\text { vous plaît? }\end{array}$ \\
\hline \multicolumn{3}{|l|}{ consulter la carte } \\
\hline \multicolumn{3}{|l|}{ choisir le menu } \\
\hline appeler le serveur & $\begin{array}{l}\text { 2. Oui, } \\
\text { j'arrive. }\end{array}$ & $\begin{array}{l}\text { 1. Monsieur, } \\
\text { (Mademoise- } \\
\text { lle), on vou- } \\
\text { drait comman- } \\
\text { der. }\end{array}$ \\
\hline \multicolumn{3}{|l|}{ attendre } \\
\hline commander le menu & $\begin{array}{l}\text { 2. Oui, } \\
\text { et comme } \\
\text { boisson? }\end{array}$ & $\begin{array}{l}\text { 1. Deux plats } \\
\text { du jour. } \\
\text { 3. Une bou- } \\
\text { teille d'eau * }\end{array}$ \\
\hline boire l'apéritif & $\begin{array}{l}\text { 1. Vous } \\
\text { prendrez } \\
\text { l'apéritif? }\end{array}$ & 2. Non, merci. \\
\hline \multicolumn{3}{|l|}{ manger } \\
\hline \multicolumn{3}{|l|}{ boire } \\
\hline demander l'addition & $\begin{array}{l}\text { 2. Oui, tout } \\
\text { de suite. }\end{array}$ & $\begin{array}{l}\text { 1. Monsieur, } \\
\text { l'addition, s'il } \\
\text { vous plaît. }\end{array}$ \\
\hline \multicolumn{3}{|l|}{ payer } \\
\hline \multicolumn{3}{|l|}{ prendre son manteau } \\
\hline dire au revoir & $\begin{array}{l}\text { Au revoir, } \\
\text { merci ou } \\
\text { bonne jour- } \\
\text { née/soirée. }\end{array}$ & Au revoir. \\
\hline
\end{tabular}

Fig. 2. Diàleg obtingut quan introduïm el llenguatge en l'esquema de la figura 1. 1, 2 i 3 indiquen l'ordre de les intervencions.

* Es pot precisar: une eau plate, gazeuse o la marca: Saint Yorre, Vittel, Vichy...

versacional Compartit perquè és:

- un espai psicològic, social i físic que identifica els interlocutors, les circumstàncies i el lloc de l'intercanvi.

- un espai conversacional en el sentit que la conversa és ritual tant en a) el seu desenvolupament (obertura, desenvolupament, clausura); b) la cooperació cap a la construcció i al manteniment de l'intercanvi; l'ús de la llengua (Bonjour Madame Durand - Bonjour Monsieur Lepois - I/ fait pas chaud ce matin - Ah non! Mais qu'est-ce que vous voulez, c'est l'hiver! - Au revoir - Au revoin); d) la utilització de "petites paraules", elements fàtics molt específics d'una llengua, que serveixen per pensar, mantenir la conversa i que al mateix temps formen part de la llengua-cultura; són paraules identificadores de la cultura i de la implicació emocional del locutor (Euh... oui, Ben... - C'est curieux! - Ah, dis donc! - Ça alors.).

- un espai compartit, donat que carateritza el lligam lingüístic i cultural comú i implica la complicitat cultural i lingüística dels interlocutors. Aquesta complicitat es basa en l'experiència comuna, sigui la història apresa a l'escola, les activitats comunes...

Les relacions entre els interlocutors es poden definir a diferents nivells, com per exemple:

- 1. Les persones desconegudes: grau d'implicació zero: neutralitat de relacions, discurs rutinari que té un objectiu purament informatiu: demanar l'hora, una adreça...

2. Les persones que saludem (veïns...): grau d'implicació variable, però espai físic compartit (ciutat, poble, barri, immoble...).

3. Les persones conegudes (col-legues...): grau d'implicació superior, donat que es comparteix l'espai cultural, professional i geogràfic.

4. Les persones molt conegudes (família, amics): grau d'implicació màxim, donat que es comparteix l'espai cultural, històric i afectiu (Fig. 3).

Farem la distinció entre dos tipus d'Espai Conversacional Compartit (E.C.C.):

a) I'E.C.C. ritualitzat tradicional: fa referència als usos socials i requereix un nivell de llenguatge centrat fonamentalment en el domini de les rutines lingüístiques: el temps, la salut, el treball, els estudis, la família, les vacances... Forma part de la vida quotidiana, on figura com un espai de renovació constant de la comunicació que s'entén així com una confirmació de la pertinença a un grup sociocultural. 


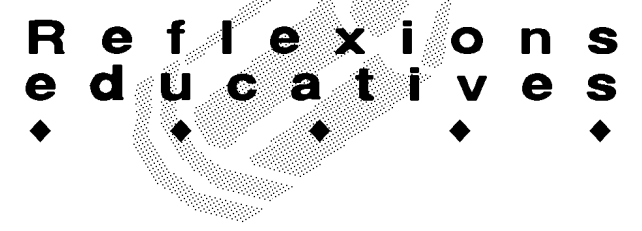

b) I'E.C.C. ritualitzat puntal: un esdeveniment, una celebració, un accident, un viatge, un incident, una aventura... Forma part de les experiències comunicatives noves, és a dir, no previstes, però que poden ocórrer i marcades per unes normes de conducta conegudes.

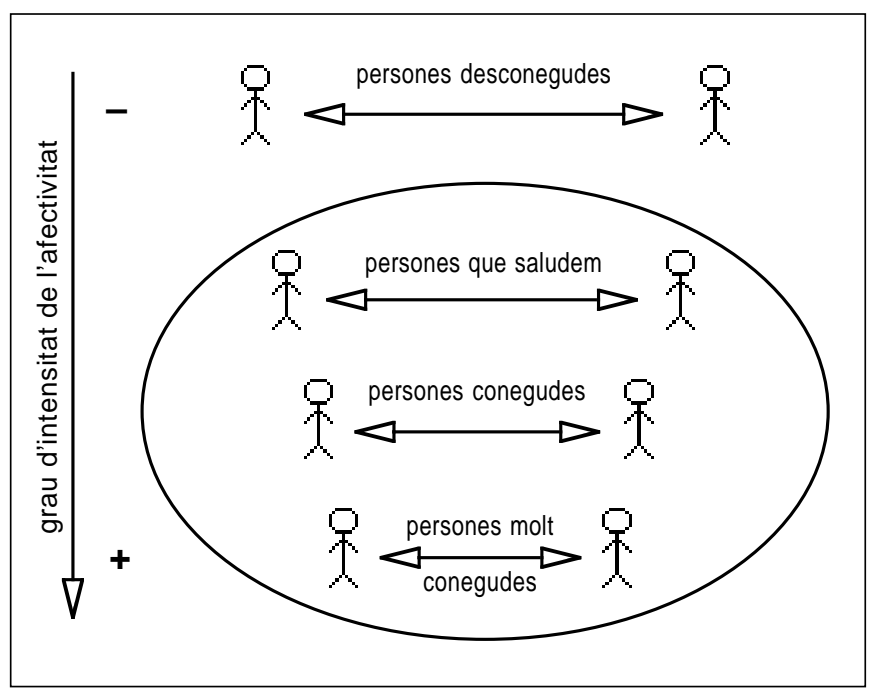

Fig. 3. Rutines lingüístiques entre diferents tipus d'interlocutors

\section{Aplicacions per a la classe}

L'ús dels escripts o esquemes permet: a) explicitar el funcionament de l'intercanvi comunicatiu; b) contrastar aquest funcionament amb el de la llengua materna; c) realitzar una sèrie d'activitats que tenen com a finalitat el coneixement i ús del ritual en la llengua.

A continuació presentem alguns exercicis que s'han de fer després d'haver treballat els diàlegs a classe. Es poden fer abans com una avaluació prèvia dels coneixements dels alumnes.

Exercici 1: Proposar frases (o mini diàlegs) on els rituals no es respecten.

P.e. - Bonjour $X$, donne-moi une bière...

Proposar nous diàlegs o noves frases.

Exercici 2: Donar una graella a doble entrada. En la primera columna es descriuen una sèrie d'accions, en la segona l'alumne ha d'afegir el contingut lingüístic que correspon a cada acció tenint en compte l'estatus de l'interlocutor ( $\mathrm{Hi}$ ha accions que no requereixen cap producció lingüística).

Exercici 3: Mesclar frases on es respecten les seqüències d'accions amb altres on no són respectades. Detectar els errors i proposar seqüències alternatives.

Exercici 4: Donar esquemes desordenats. Buscar l'ordre correcte.

Exercici 5: Donar esquemes incomplets. Què falta? Exercici 6: Introduir elements "pertorbadors" en un esquema. Mesclar els registres lingüístics. Què s'ha de modificar?

Tots aquests exercicis es faran en funció d'un treball previ i del nivell dels alumnes.

\section{Conclusió}

Hem partit d'un objectiu sociocultural sota la forma de la imatge social de la comunicació i hem intentat mostrar que, si posem la llengua dins del marc social que li correspon, podem arribar a situar l'alumne davant d'una realitat sociocultural d'una llengua.

Quan abans l'aprenentatge d'una llengua estrangera es considerava com una via d'accés al saber en la llengua, avui demanem a l'alumne que sigui un "productor" de llenguatge, que s'acostumi a dir allò que vol dir i no solament allò que pot dir. Però, per arribar a aquest objectiu cal donar-li les eines necessàries.

Aquesta preocupació general per la producció ha centrat l'interès pedagògic sobre les adquisicions lingüístiques i comportamentals. Per altra banda, l'interès per la sociocultura de "'altre" alumne ens ha portat a tenir en compte tots els aspectes de les situacions comunicatives i culturals. Però moltes vegades les anàlisis cientìiques en el llenguatge, les metodologies (que en són les conseqüències) i l'interès per l'aprenentatge significatiu o la psicologia del nen i la gestió de la informació ens han amagat la realitat d'ús de la llengua, és a dir, les condicions, les normes i les regles que ens obliguen a utilitzar un determinat tipus de llengua en una situació determinada. Un itinerari d'aprenentatge, per petit que sigui, que tingués en compte els dos components esmentats anteriorment (scripts i Espai Conversacional Compartit) podria donar a l'aprenentatge de la llengua una dimensió que justificaria plenament la seva vessant comunicativa i contribuiriria a entendre una mica millor el "funcionament" mental i cultural de "l'altre", que és, al cap i a la fi, el que queda del que s'ha après d'una llengua estrangera.

\section{Referències bibliogràfiques}

ABELSON, R.P. Psychological status of the script concept. «American Psychologist». 36, 2 (1981) 715-729.

CORSON, Y. The structure of scripts and their constituent elements. "Cahiers de Psychologie Cognitive»/European Bulletin of Cognitive Psychology. 10, 2 (1990) 157-183.

GALLISON, R. De la langue à la culture par les mots. Edit. Cle International. París. 1991.

GAONAC'H, D. Théories d'apprentissage et acquisition d'une langue étrangère. Edit. Hatier-Crédif. Paris. 1987.

LE NY, J.F. Accès au lexique et compréhension du langage: la ligne de démarcation sémantique. In P. Lecoq \& J. Segui (sous la dir. De), L'accès lexical (Lexique 8). Edit. PUL. Lile. 1989. 